\title{
Correspondence
}

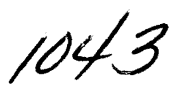

\section{Portacaval Shunt in Three Children with Alpha-1-Antitrypsin Deficiency and Cirrhosis: 9 to $12 \frac{1}{3}$ Years Later}

To the Editor:

Regarding the elegant discussion of liver transplantation recently published by Maddrey and Van Thiel (1), we would like to comment on patients with alpha1-antitrypsin deficiency and liver disease whom we saw before the extensive use of liver transplantation.

Evidence was published five years ago showing that end-to-side portacaval shunt in these patients may have favorably influenced the course of liver disease caused by alpha-1-antitrypsin deficiency (2). The operations, on two girls and one boy, were performed on June 15, 1976; March 7, 1978 and November 1, 1979, when the children were $4 \frac{1}{3}, 6 \frac{1}{2}$ and $1 \frac{1}{6}$ yr old, respectively. At the time, the option of liver transplantation was neither satisfactory nor widely available. All three children had had neonatal hepatitis and a history of bleeding esophageal varices, ascites or both. Phenotypes were PiZZ ( $\mathrm{Pi}=$ protease inhibitor). Liver function was abnormal but not gravely perturbed (Table 1).

The low serum alpha-1-antitrypsin levels were not appreciably different before and long after the portacaval shunts (Table 1). All three children had normal physical growth, and Patients 1 and 3 remain ostensibly healthy. Patient 2 was frequently ill, with a record of frequent school absenteeism. Diuretics were required intermittently for control of her ascites. Her liver function test results were abnormal at the time of portacaval shunt. Her test results worsened immediately afterward (2) but then became stable for more than $91 / 2$ yr (Table 1). In October 1987, she developed acute liver decompensation and on November 3,1987 , underwent successful orthotopic liver transplantation at the University of California at Los Angeles. It was previously reported (2) that the serum ammonia rose after portacaval shunt in all three patients and that the aminotransferase and alkaline phosphatase levels fell. The same pattern has persisted (Table 1) in Patients 1 and 3 , neither of whom has practiced any dietary restriction.

All three patients had macronodular cirrhosis at the time of portacaval shunt, with biopsy findings typical of the liver disease associated with alpha-1-antitrypsin deficiency (2). The sample obtained from the excised liver in Patient 2 after 91/2 yr and the repeat biopsy

Address reprint requests to: Thomas E. Stard, M.D., Ph.D., Department of Surtery, 3601 Fifth Ave., Falk Clinic 4 West, Pitteburgh, Pennsylvania 15213. 31/8/17082 sample in Patient 3 after $82 / 3$ yr were fixed in buffered formalin. Patient 1 refused biopsy. Paraffin sections were prepared and stained with a variety of reagents, including periodic acid-Schiff stain, after the sections were treated with diastase. A peroxidaseantiperoxidase technique with specific antibody (Dakopatts) was used to identify alpha-1-antitrypsin. A standard morphometrical method revealed 10,000 hepatocytes in each liver sample (3). The proportion of hepatocytes with alpha-1-antitrypsin granules in the cytoplasm was recorded.

Both livers remained cirrhotic, and the cytoplasm of some of the hepatocytes contained granules of alpha1-antitrypsin. Most of the granules were small and the number per cell varied greatly; they were more common at the periphery of the pseudolobules. When compared with the liver biopsy specimens obtained at the time of portacaval shunting, the severity of the cirrhosis appeared unaltered, but in Patient 2 severe intrahepatic cholestasis that had not been present before was found. In Patients 2 and 3 the hepatocytes were approximately $20 \%$ smaller than when the portacaval shunt was performed. The percentage of hepatocytes containing alpha-1-antitrypsin also was lower. In $\mathrm{Pa}$ tient 2, it was $19.3 \%$ (compared with $38.2 \%$ in the preshunt biopsy specimen and $28.5 \%$ in a biopsy sample taken 9 mo later). In Patient 3, the percentage was $19.05 \%$ (compared with $44.5 \%$ in the preshunt biopsy specimen, $48.2 \% 7 \mathrm{mo}$ after portacaval shunting, $38.7 \%$ at $13 \mathrm{mo}$ and $20.4 \%$ at $2 \mathrm{yr}, 11 \mathrm{mo}$ ) (2).

Portal diversion has been shown during the last 15 yr to palliate three congenital errors of metabolism: glycogen storage disease (3), familial hypercholesterolemia (4) and alpha-1-antitrypsin deficiency $(2,5)$. Because each of these errors can be corrected far more effectively by liver transplantation (6-8), portacaval shunts for metabolic purposes in these diseases have been almost completely and appropriately abandoned. The presence of a shunt introduces a technical risk factor at the time of transplantation. However, there may be occasional patients such as ours with alpha-1antitrypsin deficiency, reasonable liver function and serious complications of portal hypertension, who submit to lifesaving portal diversion procedures when a liver cannot be found at the appropriate time. In our patients the process of liver injury thought to be caused by the intracellular accumulation of irritating alpha1-antitrypsin particles that cannot be excreted at a normal rate (9) seems to have been slowed or stopped by portal diversion. It was previously speculated $(2,5)$ that 
TABLE 1. Chemistries before end-to-side portacaval shunt and $83 / 3$ to $12 \mathrm{yr}$ later

\begin{tabular}{|c|c|c|c|c|c|c|c|}
\hline \multirow[b]{2}{*}{ Age (yr) at testing } & \multirow[t]{2}{*}{ Normal } & \multicolumn{2}{|c|}{ Patient 1} & \multicolumn{2}{|c|}{ Patient 2} & \multicolumn{2}{|c|}{ Patient 3} \\
\hline & & $42 / 3$ & $16 \%$ & $61 / 2$ & $16^{\circ}$ & $11 / 12$ & $93 / 4$ \\
\hline Serum bilirubin $(\mu \mathrm{mol} / \mathrm{L})$ & $<20$ & 26 & 17 & 31 & 40 & $<20$ & 25 \\
\hline Serum ammonia $(\mu \mathrm{mol} / \mathrm{L})$ & $<40$ & 59 & 116 & $29-53$ & 95 & $<40$ & 75 \\
\hline Serum AST (IU/L) & $<50$ & 150 & 32 & 200 & 101 & 200 & 102 \\
\hline Serum ALT (IU/L) & $<50$ & 260 & 51 & 300 & 61 & 150 & 52 \\
\hline Alkaline phosphatase (IU/L) & $<200$ & 1,800 & 595 & 1,000 & 117 & 550 & 351 \\
\hline Prothrombin time (sec) & $11-11.5$ & 12 & 12.8 & 13 & 15 & 11.5 & 12 \\
\hline $\begin{array}{l}\text { Serum alpha-1-antitryspin } \\
(\mathrm{gm} / \mathrm{L})\end{array}$ & $>2.0$ & 0.3 & 0.5 & 0.16 & $<0.20$ & 0.30 & 0.22 \\
\hline Serum protein $(\mathrm{gm} / \mathrm{L})$ & $>65$ & 63 & 56 & 52 & 52 & 60 & 55 \\
\hline Serum albumin $(\mathrm{gm} / \mathrm{L})$ & $>30$ & 33 & 35 & 35 & 28 & 30 & 28 \\
\hline
\end{tabular}

These tests were in early October 1987, 1 mo before liver transplantation on November 3, 1987. Liver function deteriorated rapidly during the next few weeks, necessitating transplantation.

the portacaval shunt selectively damaged the rough endoplasmic reticulum where the synthetic processes of the liver are concentrated without a commensurate reduction in excretory function of the hepatocytes. The result would be a more favorable relation between deposition of the alpha globulin and its elimination from the hepatocytes. The histopathological findings in the livers of Patients 1 and 3 were consistent with this hypothesis in that the reduction in the size of the hepatocytes and in the percentage of hepatocytes containing alpha-1-antitrypsin granules noted in the earlier biopsies (2) has been maintained.

This letter is not intended to suggest that portacaval shunt for metabolic purposes is an alternative to liver transplantation. We have compiled no further cases in our practice since treating Patient 3 in 1979. It is possible that a reduction of the alpha-1-antitrypsin particles is irrelevant. Although the accumulation of this abnormal alpha-1-antitrypsin in the hepatocytes may be a crucial element in the pathogenesis of liver disease, this factor alone is not sufficient. Only a minority of patients found through pediatric screening programs to have the homozygous PiZZ phenotype, which is the marker for this congenital error, go on to develop serious liver disease (10). Infants in the PiZZ population who are at particularly high risk for chronic liver disease are those who have had a bout of neonatal jaundice (11). However, even in this group the incidence and severity of later liver disease are so variable $(12,13)$ that neither portacaval shunt nor transplantation can be considered in a prophylactic sense. Candidates for surgical therapy must self-select through their own life-threatening complications, and when that happens the selection usually is transplantation. The shunt operation has no effect on the protease inhibitor deficiency, whereas liver transplantation restores serum alpha-1-antitrypsin to normal (6).

The principal physiological function of alpha-1antitrypsin is to inhibit neutrophil elastase (14). The destruction of alveolar walls by consequent emphysema in patients with alpha-1-antitrypsin deficiency (15) presumably results from the unchecked activity of neu- trophil elastase. A favorable effect on lung disease is expected from liver transplantation, although with a maximal follow-up of only $13 \mathrm{yr}(16)$, it is too soon to be sure that this will be achieved.

\author{
Thomas E. Starzl, M.D., Ph.D. \\ Department of Surgery \\ University of Pittsburgh, \\ Pittsburgh, PA 15213 \\ KENDRICK A. PORTER, M.D. \\ Department of Pathology \\ St. Mary's Hospital and Medical School \\ University of London \\ London W2 1PG, England \\ RoNald W. BusuTtil, M.D., Ph.D. \\ Department of Surgery \\ UCLA School of Medicine \\ Los Angeles, CA 90024 \\ RUdOlPh PichlmayR, M.D., Ph.D. \\ Department of Surgery \\ University of Hannover \\ D-3000 Hannover 61, West Germany
}

\section{REFERENCES}

1. Maddrey WC, Van Thiel DH. Liver transplantation: an overview. HePaTOlogy 1988;8:948-959.

2. Starzl TE, Porter KA, Francavilla A, Iwatsuki S. Reversal of hepatic alpha-1-antitrypsin deposition after portacaval shunt. Lancet 1983;2:424-426.

3. Starzl TE, Putnam CW, Porter KA, Halgrimson CG, Corman J, Brown BI, Gotlin RW, et al. Portal diversion for the treatment of glycogen storage disease in humans. Ann Surg 1973;178:525. 539.

4. Starzl TE, Chase HP, Putnam CW, Porter KA. Portacaval shunt in hyperlipoproteinemia. Lancet 1973;2:940-944.

5. Starzl TE, Porter KA, Francavilla A. The Eck fistula in animals and humans. Curr Probl Surg 1983;20:687-752.

6. Hood JM, Koep LJ, Peters RL, Schroter GPJ, Weil R II, Redeker AG, Stard TE. Liver transplantation for advanced liver disease with alpha-1-antitrypsin deficiency. N Engl J Med 1980;302:272275.

47. Starzl TE, Bilheimer DW, Bahnson HT, Shaw BW Jr, Hardesty RL, Griffith BP, Iwatsuki S, et al. Heart-liver transplantation in a patient with familial hypercholesterolemia. Lancet 1984; 1:1382-1383. 
8. Malatack JJ, Finegold DN, Iwatsuki S, Shaw BW Jr, Gartner JC, Zitelli BJ, Roe T, et al. Liver transplantation for type I glycogen storage disease. Lancet 1983;1:1073-1076.

9. Carrell RW. Alpha-1-antitrypsin: molecular pathology, leukocytes and tissue damage. J Clin Invest 1986;78:1427-1431.

10. Sveger T. Liver disease in alpha-1-antitrypsin deficiency detected by screening of 200,000 infants. N Engl J Med 1976 294:1316-1321.

11. Ghishan FK, Green HL. Liver disease in children with PiZZ alpha-1-antitrypsin deficiency. HEPATOLOGY 1988;8:307-310.

12. Nebbia G, Hachouel M, Alagille D. Early assessment of evolution of liver disease associated with alpha-1-antitrypsin deficiency in childhood. J Pediatrics 1983;102:661-665.

13. Psacharopoulos HT, Mowat AP, Cooke PJL, Carile PA, Portmann B, Rodeck CH. Outcome of liver disease associated with alpha1-antitrypsin deficiency: implications for genetic counselling and antenatal diagnosis. Arch Dis Child 1983;58:882-887.

14. Bieth J. Elastases: structure, function and pathological role. Front Matrix Biol 1978;6:1-82.

15. Larsson C. Natural history and life expectancy in severe alpha1-antitrypsin deficiency, (PiZZ). Acta Med Scand 1978;204:345. 351.

16. Starzl TE, Demetris J, Van Thiel D. Medical progress: transplantation. New Engl J Med 1989;321:1014-1022; 1092-1099. 